\title{
Retraction Note to: The Longitudinal Incidence of Human Papillomavirus Vaccination in Spanish Primary Care in the First 6 Years After Approval
}

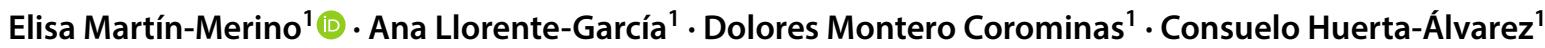

Published online: 4 July 2019

๑) Springer Nature Switzerland AG 2019

\section{Retraction Note to: \\ Pharmaceutical Medicine (2019) 33:135-144 \\ https://doi.org/10.1007/s40290-019-00268-1}

The authors have retracted this article [1] because it contains an error that has made the data unreliable. The authors have been invited to resubmit a revised version of the article. All authors agree to this retraction.

[1] Martín-Merino, E., Llorente-García, A., Montero Corominas, D. et al. Pharm Med (2019) 33: 135. https:// doi.org/10.1007/s40290-019-00268-1

The original article can be found online at https://doi.org/10.1007/ s40290-019-00268-1.

Elisa Martín-Merino emartinm@aemps.es

1 Division of Pharmacoepidemiology and Pharmacovigilance, Spanish Agency of Medicines and Medical Devices (AEMPS), Calle Campezo n ${ }^{\circ}$, Edifi cio 8, 28022 Madrid, Spain 